\title{
Research on the Mechanism of Consumers' Purchase Intention under the Xinjiang Cotton Incident
}

\author{
Ziting Zhou, Yingying Cai \\ East China University of Science and Technology, Shanghai, 200237, China
}

\begin{abstract}
Under the brand crisis triggered by the Xinjiang cotton incident, the study selected foreign brands MUJI and H\&M, which have high brand awareness, and explored the mechanism of different brand crisis response strategies on Chinese consumers' purchasing intentions, and explored in-depth the mediating effect of consumer emotions in this process, and constructed a structural equation model. The research result illustrates the correlation between emotions and corporate brand crisis response strategies and attitude towards China. It as well explains how consumer emotions play a mediating role between corporate brand crisis response strategies and purchase intentions. The study also found that consumers' negative emotions have a deeper impact on their purchase intentions. The research has fully demonstrated the internal emotions and behavioral mechanisms of consumers, guiding companies to choose appropriate response measures, clarifying corporate political positions and attitudes, and implementing appropriate corporate brand crisis strategies.
\end{abstract}

Keywords: Xinjiang Cotton Incident, Brand crisis, Consumer sentiment, Purchase Intention, Structural equation model.

\section{Introduction}

In the 21 st century, the development of information has provided a broad space for corporate brands to expand their market, but corporate brand crises are more likely to be exposed to the public. After the Xinjiang Cotton Incident this year, Chinese consumers spontaneously boycotted foreign apparel brands represented by H\&M. An unprecedented storm broke out. Improper handling of the corporate brand crisis will not only cause a decline in financial indicators such as market share and profitability, but also damage corporate operations.

This research closely follows current events with the focus on the Xinjiang cotton incident and sets it as the core background of the model. Taking the two major international brands of H\&M and MUJI as examples, the study compares consumers' emotional responses to the different actions of the two brands and conducts an in-depth study of the impact of brand crisis response strategies on consumers' purchasing intentions based on relevant literature and models in order to analyze the mediating effect of emotions on consumers' purchasing intentions and provide a theoretical and practical basis for brands to address crisis handling which could enhance consumers' purchasing intentions and consolidate domestic and foreign brands in the future.

\section{Literature Review}

Since the information is becoming more and more transparent now, it is difficult to hide the brand crisis under the exposure of the public media. Companies will implement different response methods to deal with different types of brand crises [1], while brand crisis response strategies will significantly affect consumers' cognitive evaluation, emotional response, and purchase intention [2]. The current theories about purchase intention are mainly based on consumer attitudes, perceived value, and perceived risk. Zhang Xingxing (2021) pointed out that positive attitudes of consumers will promote purchases, and negative attitudes will restrict purchases [3]; $\mathrm{Xu} \mathrm{He}$ (2020) showed that perceived value plays an intermediary role in webcasting and consumers' clothing purchase intentions [4]; Geng Xiaoqing (2021) found that consumers' perceived risk in $\mathrm{C} 2 \mathrm{C}$ transactions has a negative effect on purchase intention [5].

In summary, consumer attitudes, perceived value, and purchase intention are positively correlated, while the perceived risk is negatively correlated with purchase intention. Most of the domestic research is based on the deductive development of Western results, and the research on consumer behavior is relatively backward and needs to be indepth.

In the existing research on brands and consumers, emotions play a decisive role in consumer behavior [6]. In the face of emergencies, consumer emotions are more rapid and autonomous than rational evaluation [7], which will have an impact on decision-making [8]. Slovic et al. (2002) verified that emotions play an important role in decision-making judgments, and proposed the "emotional inspiration theory"[9]; Li Jiamin and Zhang Xiaofei (2020) also pointed out that personal emotions will strongly affect consumers' purchase intentions, since positive emotions will promote the purchase intention of consumers, and negative emotions will hinder the purchase intention of consumers [10]. Numerous studies have shown that consumer sentiment is the main factor in the change of purchase intention.

Based on the above-mentioned related theoretical research, brand crisis response strategies will affect consumer emotions and change consumers' purchasing intentions. The following basic model framework is established: Brand crisis response strategy $\rightarrow$ consumer emotions $\rightarrow$ consumer's purchasing intentions.

\section{Theoretical Model and Research Hypothesis}

\subsection{Concept Definition and Variable Measurement}

\subsubsection{Brand Crisis Response Strategy}

This research focuses on the brand crisis of the Xinjiang cotton incident, sets up scenarios and used operational 
definitions, divides the brand crisis response strategies into "anti-China measures" and "pro-China measures", and used Likert's seven-level scale to measure the degree of perception of crisis response measures to reflect the pro-Chinese and anti-Chinese degree of corporate brand crisis response strategies.

\subsubsection{Consumer Emotions}

Emotion is a mental activity produced by subjective cognitive experience and attitude towards objective things. It is an autonomous mental state produced by events or situations [11]. With reference to the ten basic emotion scales discovered by Izard [12], the study deletes the options that are prone to cognitive ambiguity in the original scale and selects four emotions of interest, pleasure, anger, and disgust, adopting the Likert Seven Level scale for measurement.

\subsubsection{Purchase Intention}

Purchase intention refers to the probability that consumers are willing to make relevant purchase behaviors. This is a manifestation of consumer psychology and a precursor factor of consumer purchase behavior [43]. This study selects the relevant items in the Spence et al. (1998) [13] and Chen (2008) [14] scales, and uses the Likert seven-level scale to determine consumers' purchase intentions.

\subsection{Theoretical Model and Hypothesis}

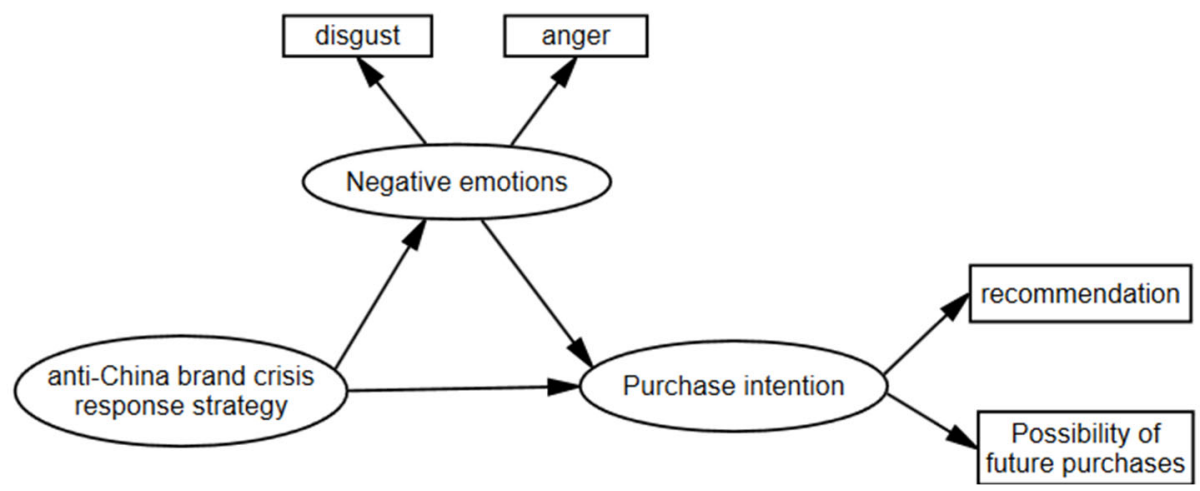

Figure 1. Model of group a

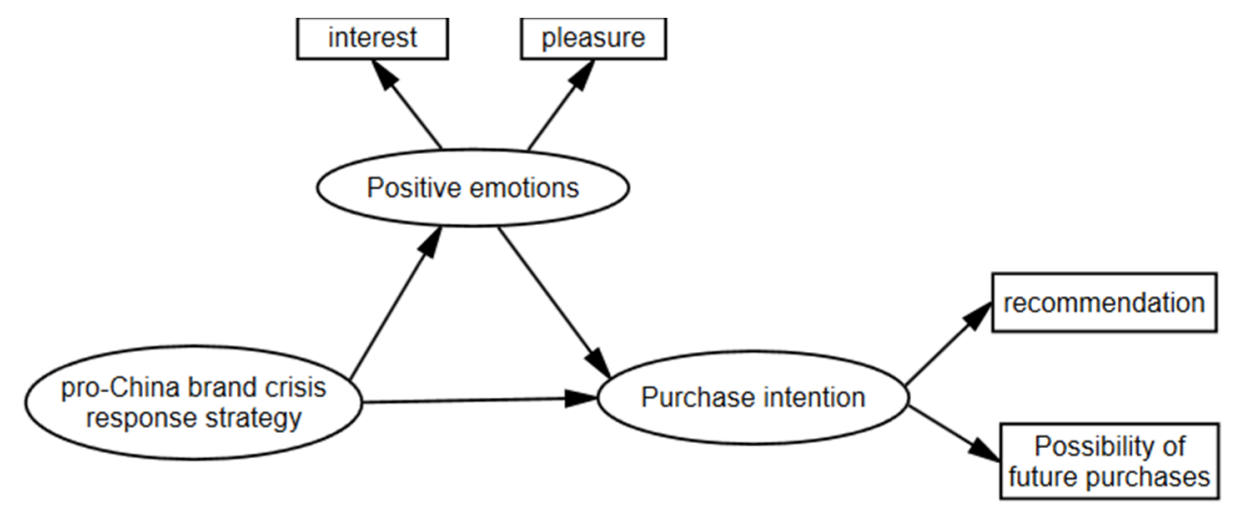

Figure 2. Model of group b

h1-1a Consumers' disgust is positively correlated with the anti-China degree of corporate brand crisis response strategies.

h1-1b Consumers' anger is positively correlated with the anti-China degree of corporate brand crisis response strategies.

h1-2a Possibility of future purchases is negatively correlated with the anti-Chinese degree of corporate brand crisis response strategies.

$\mathrm{h} 1-2 \mathrm{~b}$ The recommendation degree is negatively correlated with the anti-Chinese degree of the corporate brand crisis response strategy.

h1-3 Consumers' negative emotions play an intermediary role between the anti-China degree of the corporate brand crisis response strategy and the purchase intentions.

h2-1a Consumers' pleasant mood is positively correlated with the pro-China degree of corporate brand crisis response strategies.

h2-1b Consumers' interest and emotions are positively correlated with the pro-China degree of corporate brand crisis response strategies. h2-2a Possibility of future purchases is positively correlated with the pro-China degree of corporate brand crisis response strategies.

h2-2b The recommendation degree is positively correlated with the pro-China degree of the corporate brand crisis response strategy.

h2-3 Consumers' positive emotions play an intermediary role between the pro-China degree of corporate brand crisis response strategies and purchase intentions.

\section{Research Design and Results}

\subsection{Purpose}

This experiment selects foreign brands MUJI and H\&M, which have a high brand awareness rate. The purpose is to study the influence mechanism of different brand crisis response strategies on the purchase intention of Chinese consumers under the brand crisis caused by the Xinjiang cotton incident, and to explore in-depth The mediating effect of consumer emotions in this process. 


\subsection{Experimental Design}

Participant control: The age group was $18-45$ years old, and a small-scale pre-experiment was conducted on the population within this age range, and the content was a brand recognition test. The results show that this age group has relatively consistent recognition rates for the two brands selected in this experiment.

This experiment is designed as an inter-group experiment, in order to balance or reduce the error caused by the difference of the subjects. In this study, all participants in the experiment were divided into two groups according to the parity of the end numbers of the mobile phones of the subjects. Participants with odd numbers ended up in group A to answer questions in group A, and even numbers ended in group B to answer questions in group B.

First, the two groups of subjects read a brief summary from the regular press conference held by the Ministry of Foreign Affairs on March 25, 2021. Spokesperson Hua Chunying responded to the Xinjiang cotton incident as a condensed summary of the hot issue, about 85 words. Then group A read an excerpt from the public statement issued by H\&M, Group $B$ read an excerpt from the public statement issued by MUJI on this incident. Finally, the consumer's mood and purchase intention are measured.

As subjects' responses to the questionnaire are tacitly biased-they are more inclined to agree to all the questions or make positive comments, the questionnaire uses a mixture of positive and negative questions to measure consumer sentiment, which consumes more of the subjects. Cognitive resources make the subjects more engaged.

In the subsequent data analysis, data processing is performed in SPSS for the reverse scoring questions, and the code conversion is performed to re-scoring.

\subsection{Results}

\subsubsection{Questionnaire Results}

A total of 258 questionnaires were issued and 251 questionnaires were returned, with a recovery rate of $97.3 \%$.

The data was screened through quality control questions, and 217 valid questionnaires were finally recovered, including 108 for group A (H\&M) and 109 for group B (MUJ), with an effective rate of $86.5 \%$. It satisfies the large sample requirements of the structural equation model and also meets the requirements of experimental balance.

\subsubsection{Experimental Grouping Validity Test}

The Bonferroni method in the analysis of variance was used to test the grouping validity of this experiment. The results showed that the $\mathrm{p}$-value $<0.05$ rejected the 0 hypothesis, that is, the difference between the samples was significant.

Therefore, the grouping of this experiment is effective. It can be considered that in the face of experimental stimulus- the company's different brand crisis response strategies, consumers' purchase intentions are significantly different.

\subsubsection{Reliability and Validity Test}

(1) Questionnaire reliability test

In this study, SPSS was used. The research uses Cronbach's $\alpha$ coefficient method to detect whether the data reliability meets the standard.

The questionnaire reliability test results of group A and group B showed that the standardized Cronbach's coefficients were 0.821 and 0.74 , respectively, indicating that the consistency of the questionnaire data is acceptable, and subsequent research can be carried out.

(2) Structural validity test

This study uses AMOS 21.0 to test the validity of the structure. The fit index results of model A: $\mathrm{CMIN} / \mathrm{DF}=1.608$, $\mathrm{NFI}=0.985, \quad \mathrm{IFI}=0.994, \quad \mathrm{TLI}=0.98, \quad \mathrm{CFI}=0.994$, RMSEA $=0.075$. The fit index results of model $B$ : $\mathrm{CMIN} / \mathrm{DF}=1.719, \quad \mathrm{NFI}=0.954, \quad \mathrm{IFI}=0.98, \quad \mathrm{TLI}=0.93$, $\mathrm{CFI}=0.979, \mathrm{RMSEA}=0.082$.

Taken together, all the data from the two experiments have a good fit with their respective models, and the data fit well with the model.

\subsubsection{Correlation Analysis}

This study uses Pearson correlation analysis to examine the degree of correlation between the variables and their correlation direction. Table 1 shows that in experiment a, the degree of anti-China brand crisis response strategy is significantly positively correlated with negative emotions of disgust and anger at the level of 0.01 .

Compared to possible purchases in the future, the degree of recommendation has a stronger correlation with negative emotions. Consumers' purchase intentions - the degree of possible purchase and recommendation in the future-are significantly negatively correlated with the degree of antiChina corporate brand crisis response strategies. So far, it is assumed that h1-1a, h1-1b, h1-2a, and h1-2b have all been verified.

In the same way, Table 2 shows that in experiment $b$, the pro-Chinese degree of brand crisis coping strategies and the positive emotions of pleasure and interest are significantly positively correlated at the level of 0.01 . Consumers' pleasure and interest are significantly positively correlated with purchase intentions. Pleasant emotions with higher energy show a stronger positive correlation between recommendation and possible future purchases than interest. And compared to possible purchases in the future, the degree of recommendation has a higher positive correlation with consumers' perception of the company's degree of pro-China response to the brand crisis. Therefore, it is assumed that h21a, h2-1b, h2-2a, and h2-2b have also been verified.

Table 1. Group A: Pearson correlation coefficient

\begin{tabular}{|c|c|c|c|c|c|}
\hline & $\begin{array}{l}\text { anti-China brand crisis } \\
\text { response strategy }\end{array}$ & disgust & anger & Recommendation & $\begin{array}{l}\text { Possibility of } \\
\text { future purchases }\end{array}$ \\
\hline $\begin{array}{c}\text { anti-China brand crisis response } \\
\text { strategy }\end{array}$ & ( & & & & \\
\hline disgust & $.251^{* *}$ & 1 & & & \\
\hline anger & $.274^{* *}$ & $.886^{* *}$ & 1 & & \\
\hline recommendation & $-.418^{* *}$ & $-.537^{* *}$ & $-.515^{* *}$ & 1 & \\
\hline Possibility of future purchases & $-.263^{* *}$ & $-.430^{* *}$ & $-.460^{* *}$ & $.747^{* *}$ & 1 \\
\hline
\end{tabular}


Table 2. Group B: Pearson correlation coefficient

\begin{tabular}{|c|c|c|c|c|c|}
\hline & $\begin{array}{l}\text { pro-China brand crisis } \\
\text { response strategy }\end{array}$ & pleasure & interest & Recommendation & $\begin{array}{l}\text { Possibility of } \\
\text { future purchases }\end{array}$ \\
\hline $\begin{array}{c}\text { pro-China brand crisis response } \\
\text { strategy }\end{array}$ & ( & & & & \\
\hline pleasure & $.335 * *$ & 1 & & & \\
\hline interest & $.350 * *$ & $.382 * *$ & 1 & & \\
\hline recommendation & $.564 * *$ & $.402 * *$ & $.365 * *$ & 1 & \\
\hline Possibility of future purchases & $.304 * *$ & $.400 * *$ & $.202 *$ & $.325 * *$ & 1 \\
\hline
\end{tabular}

**. is significantly different from zero at the 0.01 level (two-tailed).

*. is significantly different from zero at the 0.05 level (two-tailed).

\subsubsection{Mediating Effect Test}

In this study, the Bootstrap method was used to test the mediation effect. Table 3 and Table 4 are the results of Bootstrap sampling 1000 times with the confidence interval set to $95 \%$.

In group a, the total effect, indirect effect, and direct effect are all significant, and the confidence interval does not include 0 . Therefore, the mediating effect of negative emotions has been verified. And because the indirect and direct effects are both significant, the negative emotions of consumers play a part in the mediating role. It can be calculated that the indirect effects account for $32.067 \%$ of the total effects. Hypothesis h1-3 The mediating role of negative emotions has been verified.

In group b, the total effect and indirect effect were significant and the confidence interval did not include 0 , so the mediating effect of positive emotions was verified. However, the direct effect is not significant, and the confidence interval contains 0 , so it is believed that the positive emotions of consumers play a completely mediating role. Therefore, it is hypothesized that the mediating role of h2-3 positive emotions has been verified.

Table 3. Group A: Mediating effect test

\begin{tabular}{|c|c|c|c|c|}
\hline \multirow{2}{*}{ route } & \multirow{2}{*}{\multicolumn{2}{|c|}{ Standardized Total Effects }} & \multicolumn{2}{|c|}{ Bias-corrected 95\%CI } \\
\hline & & & Lower Bounds & Upper Bounds \\
\hline \multirow{7}{*}{$\begin{array}{l}\text { The anti-China degree of brand crisis } \\
\text { response strategy } \rightarrow \text { Negative emotions } \\
\rightarrow \text { Purchase intention }\end{array}$} & -0.421 & $* *$ & -0.599 & -0.195 \\
\hline & \multirow{2}{*}{\multicolumn{2}{|c|}{ Standardized Direct Effects }} & \multicolumn{2}{|c|}{ Bias-corrected 95\%CI } \\
\hline & & & Lower Bounds & Upper Bounds \\
\hline & -0.286 & $* *$ & -0.175 & -0.027 \\
\hline & \multirow{2}{*}{\multicolumn{2}{|c|}{ Standardized Indirect Effects }} & \multicolumn{2}{|c|}{ Bias-corrected $95 \% \mathrm{CI}$} \\
\hline & & & Lower Bounds & Upper Bounds \\
\hline & -0.135 & $* *$ & -0.227 & -0.4 \\
\hline
\end{tabular}

Table 4. Group B: Mediating effect test

\begin{tabular}{|c|c|c|c|c|}
\hline \multirow{2}{*}{ route } & \multirow{2}{*}{\multicolumn{2}{|c|}{ Standardized Total Effects }} & \multicolumn{2}{|c|}{ Bias-corrected 95\%CI } \\
\hline & & & Lower Bounds & Upper Bounds \\
\hline \multirow{7}{*}{$\begin{array}{l}\text { The pro-China degree of brand crisis } \\
\text { response strategy } \\
\rightarrow \text { Positive emotions } \\
\rightarrow \text { Purchase intention }\end{array}$} & 0.769 & ** & 0.544 & 1.227 \\
\hline & \multirow{2}{*}{\multicolumn{2}{|c|}{ Standardized Direct Effects }} & \multicolumn{2}{|c|}{ Bias-corrected $95 \% \mathrm{CI}$} \\
\hline & & & Lower Bounds & Upper Bounds \\
\hline & 0.383 & Not significant & -0.223 & 0.76 \\
\hline & \multirow{2}{*}{\multicolumn{2}{|c|}{ Standardized Indirect Effects }} & \multicolumn{2}{|c|}{ Bias-corrected $95 \% \mathrm{CI}$} \\
\hline & & & Lower Bounds & Upper Bounds \\
\hline & 0.385 & ** & 0.158 & 1.31 \\
\hline
\end{tabular}

Note: ** means $\mathrm{P}<0.01$

\section{Research Conclusions and Inspiration}

This research specifically explores the relationship between the degree of pro-China and anti-China companies, positive and negative emotions of consumers, and consumer purchase intentions. It combines various perspectives such as emotion theory and consumer purchase intentions, constructs a structural equation model, and the model was placed under the Xinjiang Cotton Incident for specific treatment.

From the experiment, it is concluded that the negative emotion of consumers is positively related to the degree of anti-Chinese corporate brand crisis response strategy, and it plays an intermediary role between the anti-Chinese degree of corporate brand crisis strategy and purchase intention; consumers' positive emotions are positively correlated with the pro-Chinese degree of corporate brand crisis response strategies, and play an intermediary role between the proChinese degree of corporate brand crisis response strategies and purchase intentions.

Based on this, this research fully demonstrates the internal emotions and behavioral mechanisms of consumers, guides companies to choose appropriate response measures, considers consumer emotions according to the environment, background, and culture of consumers, clarifies corporate political positions and attitudes, and implements appropriate corporate brand crisis strategy. It is worth mentioning that the study found that consumers' negative emotions have a deeper impact on their purchase intentions. 
Looking back at the scenario of this study, on March 24, 2021, the "CYL Central Committee" pointed the spearhead of the BCI and Xinjiang cotton enterprise crisis at the H\&M brand, and pushed the brand crisis to a climax of public opinion, triggering a collective resonance among the domestic masses. After the outbreak of H\&M's boycott of Xinjiang cotton, many celebrities canceled their cooperation with the brand. These brands could not be found on major domestic ecommerce platforms such as Taobao and Tmall, and no one paid attention to the brand in domestic offline stores.

After the company's stock price plummeted and sales plunged, the H\&M brand once again stated that the group does not represent any political stance and it respects Chinese consumers so it will purchase sustainable cotton through a global certification third party. However, domestic consumers believe that this statement is shunned. The negative sentiment is still high and unabated.

In conclusion, domestic consumers have a strong emotional response to the brand crisis in which the corporate brand reaches the political bottom line, and the publics' tolerance and ambiguity towards the corporate is low. There is no ambiguity about the degree of pro-Chinese and antiChinese attitude, and it is non-negotiable in this kind of crisis.

\section{References}

[1] Coombs W T. An Analytic Framework for Crisis Situations: Better Responses From a Better Understanding of the Situation[J]. Journal of Public Relations Research, 1998, 10(3):177-191.

[2] KABAK I W, SIOMKOS G J.How Can an Industrial Crisis Be Managed Effectively[J].Industrial Engineering, 1990, 22(6):18 21.

[3] Huo Weihang. Research on the Moderating Effect of Internet Word of Mouth on Consumer Attitude Perception and Purchase Intention [J]. Journal of Liaoning University of Technology (Social Science Edition), 2020, 22(02): 51-54.
[4] Zhang Xingxing, Xu Jin. Analysis of the relationship between public welfare marketing, consumer brand attitude and purchase intention $[\mathrm{J}]$. Business Economics Research, 2021(10): 77-79.

[5] Gao Jinxiu, Chen Yuemei. A review of research on perceived risk and consumers' online purchase intention[J]. Jiangsu Science and Technology Information, 2020, 37(17): 38-40.

[6] Geng Xiaoqing. Perceived Risk, Emotional Trust and Purchase Intention in C2C Transactions-An Empirical Study Based on WeChat Moments Transactions[J]. China Circulation Economy, 2021, 35(07): 75-84.

[7] ZAJONC R B. Feling and Thinking: Preferences Ned no Inferences.[J]. American Psychologist, 1980, 35(2):151 175.

[8] LEDOUX J. The Emotional Brain[M].New York: Simon \& Schuster, 1996.

[9] Slovic Paul, Finucane Melissa, Peters Ellen, MacGregor Donald G. Rational actors or rational fools: implications of the affect heuristic for behavioral economics[J]. The Journal of Socio-Economics, 2002,31(4).

[10] Li Jiamin, Zhang Xiaofei. The influence of brand perception value on customers' repeat purchase intention: the mediating effect of customer emotions[J]. Business Economics Research, 2020(18): 63-66.

[11] (United States) Shita, (United States) Karat. Emotional Psychology: China Light Industry Press, 2015.03.

[12] Izard C E. Human Emotions[M]. Boom Koninklijke Uitgevers, 1977.

[13] Coombs W.Timothy. An Analytic Framework for Crisis Situations: Better Responses From a Better Understanding of the Situation[J]. Journal of Public Relations Research, 1998, 10(3):177-191.

[14] Chen Mei-Fang. An integrated research framework to understand consumer attitudes and purchase intentions toward genetically modified foods[J]. British Food Journal, 2008, 110(6): 559-579. 